\title{
Obituary jean rives
}

\section{F. Corcione}

(C) Springer-Verlag 2012

It is Easter Eve, and Jean Bernard Flament is on the phone. $\mathrm{He}$ is probably phoning to exchange Easter greetings as always throughout our long friendship. But this time, it is not to wish me a Happy Easter.

"The Patron is dead", said Jean Bernard, and a shiver ran right through me. The Patron, Jean Rives, was my mentor in surgery, but above all in life.

He was elderly and ailing, but the news still came as a surprise, and at once I felt more fragile, more alone.

And now I would like to portray him for you as I remember him.

Who was J. Rives? First of all, he was the Patron, a title I have never heard given to anyone else. Everyone called him the Patron; everyone recognised his superiority, charisma, experience, and culture. A man who rationalised every gesture and every sentence, strict with others, but first and foremost, with himself. It is said that on the day he passed his schoolleaving certificate, instead of celebrating with his friends, he went to study for the university entrance examinations.

Who was Jean Rives? A man of surgical rationality. He was the first to perform the technique of positioning a mesh in a difficult space to treat inguinal hernia, and his technique, still valid today, was the basis for the laparoscopic technique. His technique, which involves positioning an intraparietal prosthesis, is still the "gold standard" in the treatment of ventral hernia, and we are talking about ideas and techniques dating back 50 years, and which have stood the test of time.

Who was J. Rives?

A strict, but good man, a lover of art and sailing, with a thirst for life. I worked with him for 1 year, but I have

F. Corcione ( $\square)$

Turin, Italy

e-mail: francesco.corcione@ospedalideicolli.it always remained close to him, considering him as a father figure. We went away for travel together twice (he was already retired), and it was seeing him outside the hospital environment that I was able to appreciate his great human, artistic, and cultural qualities. Like all his trainees, upon his retirement, I received a book that I jealously conserved: $U n$ egard sur la Chirurgie. A compendium of teachings that only he could offer his students: culture, knowledge of things, and wisdom shine through every page. The book is divided into several chapters relating to his life. It is one of the few books I take down from the shelf every now and then to reread a chapter or a part, and I appreciate it more and more each time. In Jean Rives, we trainees have lost the Patron, our point of reference, one who could always give you advice. Surgeons have lost a brilliant man who made the history of surgery.

His greatest teaching? He was retired and living in Paris. He was 68 years old and had not set foot in an operating theatre, nor frequented a conference room since the day of his retirement. It was one of the last times I met him personally. We met at Fouquet's in the Champs Elysées as two friends. I gave him yet another Marinella tie and talked about humdrum matters. In response to my repeated attempts to invite him to Naples for some Congress or other, he adopted that stern expression that he wore when he had something important to say and said: "My dear Franceso, I'm almost 68 years old, and even though I' $m$ in good health, and I could still work, but according to the WHO, statistically speaking, in 5 years' time, I'll be a dead man. Why not spend these last 5 years finally doing some travelling, seeing an exhibition, or admiring a view or a beautiful woman, instead of locking myself away in a conference room to exchange false pleasantries with colleagues?" Rationality until the end.

Thank you, Patron, for all you gave us. 